OPEN ACCESS

Edited by:

Nihal Ahmad,

University of Wisconsin-Madison,

United States

Reviewed by:

Nicola Pimpinelli,

University of Florence, Italy

Mauro Alaibac,

University of Padua, Italy

*Correspondence:

Li Wang

w18062575475@163.com

Cheng Xu

xucheng11med@163.com

Specialty section:

This article was submitted to

Skin Cancer,

a section of the journal

Frontiers in Oncology

Received: 26 January 2021 Accepted: 02 March 2021

Published: 23 March 2021

Citation:

Wu Q, Xu C and Wang L (2021)

A Patient With Focal Myositis and

Primary Cutaneous Diffuse Large B-Cell Lymphoma: A Case Report.

Front. Oncol. 11:658907.

doi: 10.3389/fonc.2021.658907

\section{A Patient With Focal Myositis and Primary Cutaneous Diffuse Large B-Cell Lymphoma: A Case Report}

\author{
Quanxin $W u^{1}$, Cheng $X u^{2 *}$ and Li Wang ${ }^{1 *}$ \\ ${ }^{1}$ Cadre Ward Two, General Hospital of Central Theater Command of the People's Liberation Army, Wuhan, China, \\ 2 Department of Oncology, General Hospital of Central Theater Command of the People's Liberation Army, Wuhan, China
}

We report a rare case of a 92-year-old male, with a history of statin/ezetimibe intake, complained of pain and swelling of left forearm. The patient was diagnosed with focal myositis at first. Symptoms aggravated after 2 months of immunomodulatory therapy, and accompanied with protrusion lesion at left elbow. Biopsy of the protrusion lesion turned out to be primary cutaneous diffuse large B-cell lymphoma.

Keywords: statin, ezetimibe, focal myositis, PCDLBCL, CK-MB

\section{INTRODUCTION}

Focal myositis (FM) is a rare and benign dysimmune disease characterized as a rapidly growing solitary mass within a single muscle, which usually involved in lower limbs and experienced selfregression in most cases (1). Although several reported cases suggest some triggering factors such as nerve lesions, traumatic muscle lesions and autoimmune diseases (2-4), the etiology of FM remains unclear.

Primary cutaneous diffuse large B-cell lymphoma (PCDLBCL), leg type is a rare malignancy, which make up approximately $4 \%$ of all cutaneous lymphomas and $20 \%$ of all primary cutaneous B cell lymphomas (CBCLs) (5). PCDLBCL commonly occurs on one or both legs, with 10 to $15 \%$ of cases involving other sites. The 5-year survival of PCDLBCL is approximately $50 \%$, which is far worse than other CBCLs $(6,7)$.

Here we report an old male patient with left forearm lesion, considered FM at first, while diagnosed with PCDLBCL 4.5 months later, and the patient finally succumbed to severe infection.

\section{CASE PRESENTATION}

A 92-year-old male, claimed left forearm swelling for 5 months, and aggravated with pain for 3 weeks. The patient denied recent special illness, travel and injury. Medical history included hypertension, sick sinus syndrome, cardiac pacemaker implantation and hyperlipemia. He had taken rosuvastatin $10 \mathrm{mg} /$ ezetimibe $10 \mathrm{mg}$ discontinuously for 20 months and withdrawn both for 5 months. Current medications are Amlodipine Besylate.

Physical examination showed Lateral elbow joint swelling and obvious tenderness of left forearm. Laboratory test showed elevated level of creatine phosphate kinase isoenzyme (CK-MB $85.52 \mathrm{ng} / \mathrm{ml}$ ), erythrocyte sedimentation rate (ESR), C-reactive protein (CRP) and Carcinoembryonic antigen (CEA) were within normal ranges. Antinuclear antibody assay 
showed positive result. The patient refused to accept magnetic resonance imaging, instead, Ultrasonography was performed and showed hypo-echoic area in superficial fascia layer of the left forearm (Figure 1). Ultrasonography guided incisional muscle biopsy were performed. Muscle biopsy (Figures 2A, B) showed focal muscle fiber degeneration, increased perimysial cells, and a few inflammatory cells infiltrate around the interstitial blood vessels.

Patient was diagnosed with focal myositis after a multidisciplinary consultation and treated with prednisone (initial dose $30 \mathrm{mg}$ po qd, $5 \mathrm{mg}$ dose reduction per week) and leflunomide (10 mg po qd). Left forearm swelling and tenderness improved accompanied with the decrease of CK-MB level. One month later, left forearm swelling aggravated. Leflunomide was replaced by methotrexate (10 mg po per week), and dosage of prednisone was increased to $30 \mathrm{mg}$ po qd and kept for one month. The serum level of CK-MB decreased to normal and the dosage of prednisone was reduced to $25 \mathrm{mg}$ po $\mathrm{qd}$. But since then left forearm swelling was getting worse, accompanied with protrusion lesion at left elbow (Figure 3) and elevated skin temperature in local, meanwhile the patient claimed severe fatigue and lost self-care ability, regimen of methotrexate plus prednisone was abandoned. Another blood test showed an elevated serum CEA level (9.45 ng/ml), CRP level $(174.15 \mathrm{mg} / \mathrm{ml})$ and white blood cell count $\left(11.9 * 10^{9} / \mathrm{L}\right)$. Chest radiography indicated the existence of infection and Interstitial inflammation of both lungs. Protrusion lesion biopsy of left elbow was taken and antibiotics were used to control infection. The protrusion lesion biopsy turned out to be PCDLBCL (Figures 2C, D), immunohistochemical staining: PCK (-), VIM (+), S-100 (-), HMB45 (-),CD3 (+, sporadic), CD20 (+, diffused), CD30 (-), Ki67 $(+,>90 \%)$, EBER $(-), \operatorname{ALK}(-)$, CyclinD1 (-), CD5 (+, sporadic), CD15 (-), PAX-5 (+), CD79a (+), CD10 (-), CD21 (-), Bcl-6 (+), Mum-1 (+), P53 (+, sporadic), C-myc (+, 30\%), Bcl-2 (+, diffused).
Due to poor physical condition and severe lung infection, patient was suggested with best supportive care and died of respiratory failure. Dynamic change of serum CK-MB levels during the course were shown in Figure 4. Written informed consent was obtained from the patient at the diagnosis of PCDLBCL, ethical approval was waived according to the Declaration of Helsinki.

\section{DISCUSSION}

FM shared some clinical features with many diseases such as nodular or granulomatous myositis and soft tissue tumors, which brings difficulties for FM diagnosis. Clinical symptoms, magnetic resonance imaging (MRI), blood tests and biopsy help to make an accurate diagnosis. In our case, despite the lack of MRI, clinical course, physical examination, elevated CK-MB and pathology support the diagnosis.

In this case, the patient has received rosuvastatin/ezetimibe for a long time before the occurrence of left forearm tenderness. Statins are a group of drugs that reduce the levels of triglycerides and cholesterol in blood by inhibiting HMG-CoA reductase, an enzyme involved in rate limiting step in cholesterol synthesis, the incidence of statin-induced myotoxicity is estimated as $0.1-0.5 \%$ in cases of monotherapy (8). Ezetimibe inhibits cholesterol absorption from the small intestine by blocking the NiemannPick C1-like protein (9). Both statins and ezetimibe intake are reported to be associated with induction of myositis (10-12).

Interestingly, Ye et al. showed that statin intake may reduce the risk of diffuse large B cell lymphoma (13). Though statins may play a role in cancer prevention through cholesterol and cholesterol independent pathways (14-16), statins may induce myositis in rare situations, and inflammation is one of the cancer-causing factors $(17,18)$. In addition to our report, we

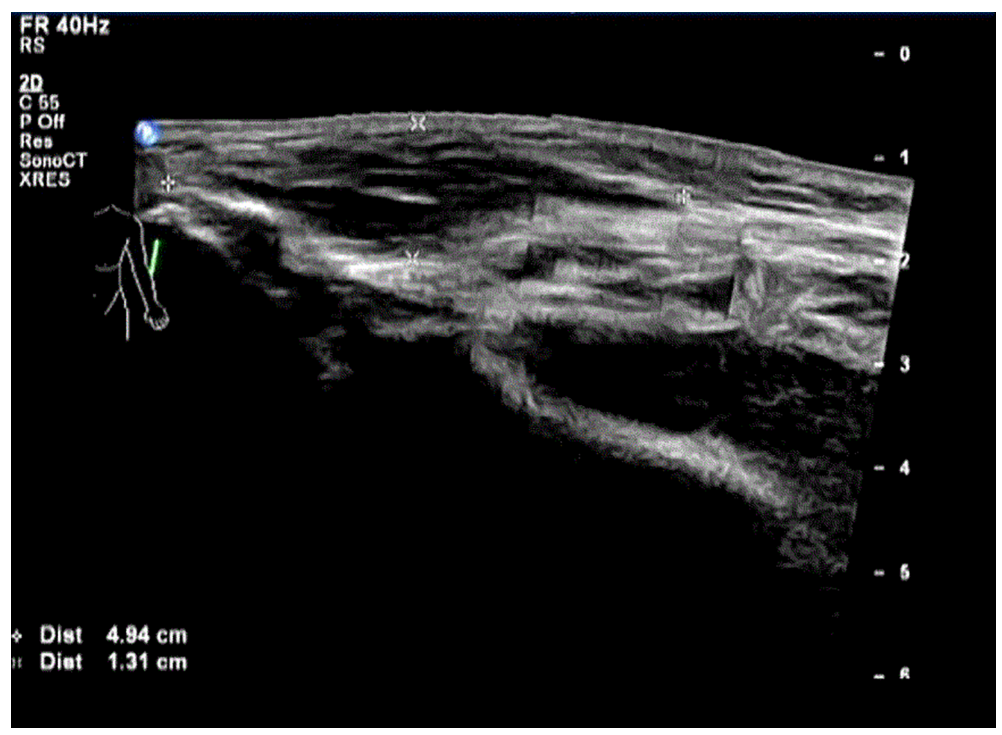

FIGURE 1 | Ultrasonography of left forearm before the diagnosis of focal myositis. 


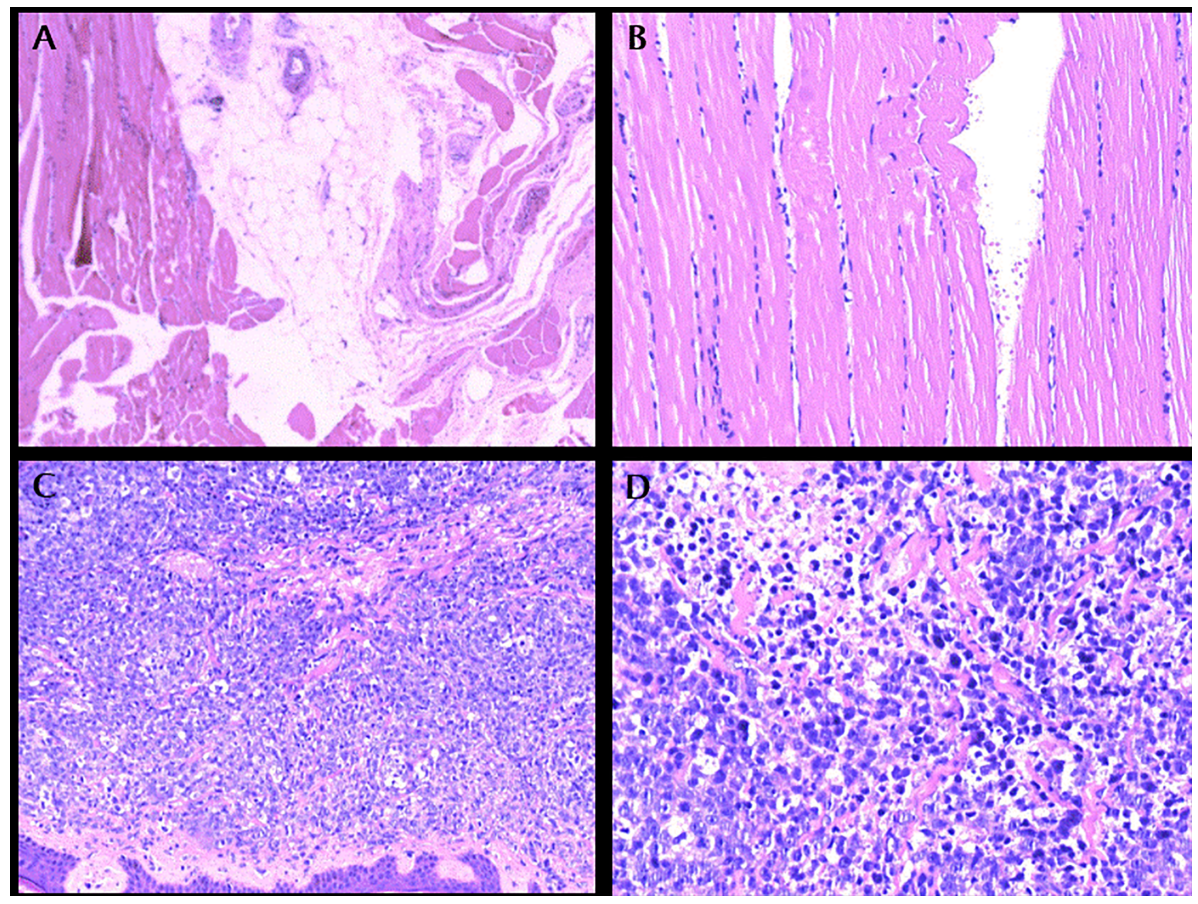

FIGURE 2 | (A): left forearm biopsy, HE × 100. (B): left forearm biopsy, HE $\times 200$. (C): Protrusion lesion biopsy of left elbow, HE $\times 100$. (D): Protrusion lesion biopsy of left elbow, HE $\times 400$.

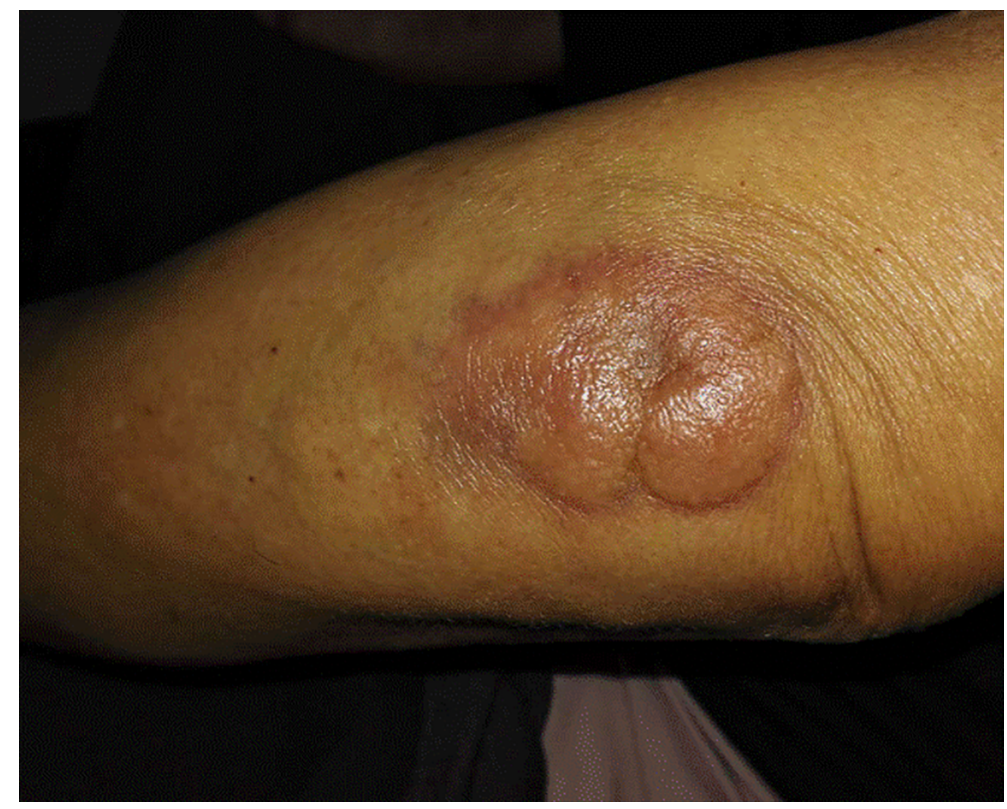

FIGURE 3 | Protrusion lesion of left elbow. 


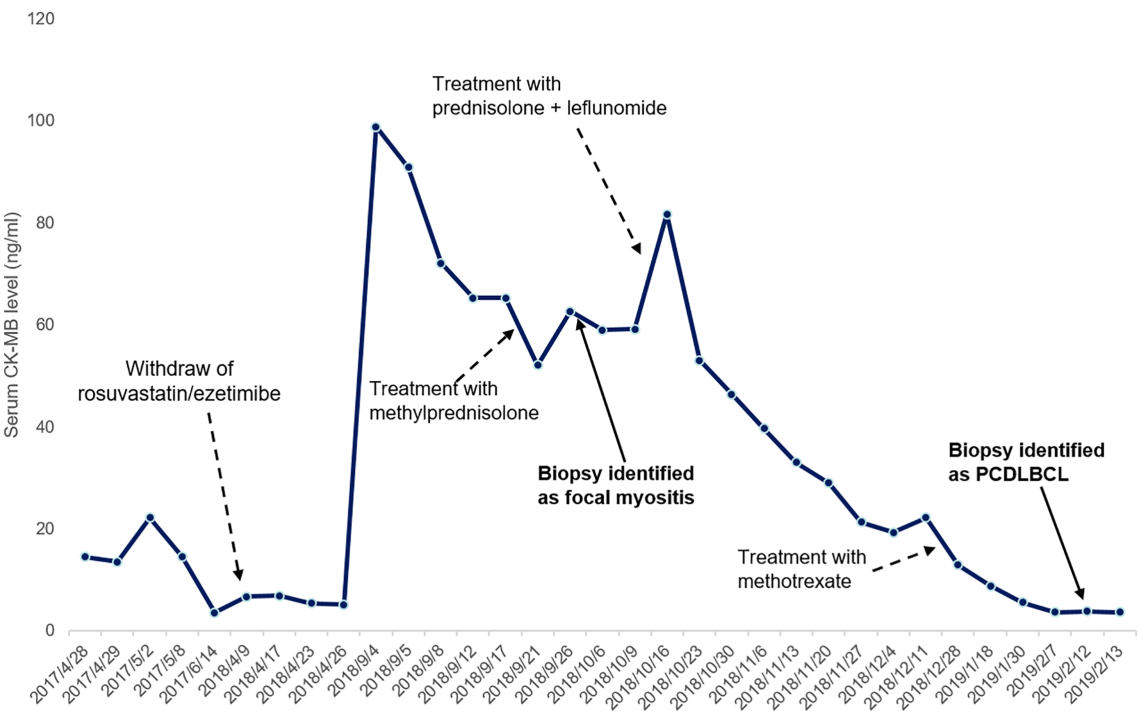

FIGURE 4 | Dynamic change of serum CK-MB levels during the course.

noticed another reported case diagnosed with both statininduced myopathy and extranodal marginal zone lymphoma (19). As we know, inflammation is one of the cancer-causing factor, in this case, the persistent focal myositis, possibly caused by statins/ezetimibe, may play a role in the oncogenesis of primary cutaneous large B-cell lymphoma.

\section{DATA AVAILABILITY STATEMENT}

The original contributions presented in the study are included in the article/supplementary material. Further inquiries can be directed to the corresponding authors.

\section{ETHICS STATEMENT}

The studies involving human participants were reviewed and approved by the ethics committee of the General Hospital of

\section{REFERENCES}

1. Devic P, Gallay L, Streichenberger N, Petiot P. Focal myositis: A review. Neuromuscul Disord NMD (2016) 26:725-33. doi: 10.1016/j.nmd.2016.08.014

2. Lunde HM, Skeie GO, Bertelsen AK, Karlsen B, Miletic H, Lindal S, et al. Focal myositis-neurogenic phenomenon? Neuromuscul Disord NMD (2012) 22:350-4. doi: 10.1016/j.nmd.2011.10.023

3. Auerbach A, Fanburg-Smith JC, Wang G, Rushing EJ. Focal myositis: a clinicopathologic study of 115 cases of an intramuscular mass-like reactive process. Am J Surg Pathol (2009) 33:1016-24. doi: 10.1097/PAS.0b013e31819e63fe

4. Sarui H, Maruyama T, Ito I, Yamakita N, Takeda N, Nose M, et al. Necrotising myositis in Behcet's disease: characteristic features on magnetic
Central Theater Command. The patients/participants provided their written informed consent to participate in this study. Written informed consent was obtained from the individual(s) for the publication of any potentially identifiable images or data included in this article.

\section{AUTHOR CONTRIBUTIONS}

QW offered the case and collected the data. CX prepared the manuscript. LW revised the manuscript. All authors contributed to the article and approved the submitted version.

\section{ACKNOWLEDGMENTS}

We thank the patient for his cooperation and support for academic communication, and thank the department of pathology for providing diagnostic support.

resonance imaging and a review of the literature. Ann Rheum Dis (2002) 61:751-2. doi: 10.1136/ard.61.8.751

5. Pinter-Brown LC. Diagnosis and Management of Cutaneous B-cell Lymphoma. Dermatol Clinics (2015) 33:835-40. doi: 10.1016/j.det.2015.05.003

6. Vermeer MH, Geelen FA, van Haselen CW, van Voorst Vader PC, Geerts ML, van Vloten WA, et al. Primary cutaneous large B-cell lymphomas of the legs. A distinct type of cutaneous B-cell lymphoma with an intermediate prognosis. Dutch Cutaneous Lymphoma Working Group. Arch Dermatol (1996) 132:1304-8. doi: 10.1001/archderm.132.11.1304

7. Grange F, Bekkenk MW, Wechsler J, Meijer CJ, Cerroni L, Bernengo M, et al. Prognostic factors in primary cutaneous large B-cell lymphomas: a European multicenter study. J Clin Oncol Off J Am Soc Clin Oncol (2001) 19:3602-10. doi: 10.1200/JCO.2001.19.16.3602 
8. Sirvent P, Mercier J, Lacampagne A. New insights into mechanisms of statinassociated myotoxicity. Curr Opin Pharmacol (2008) 8:333-8. doi: 10.1016/ j.coph.2007.12.010

9. Garcia-Calvo M, Lisnock J, Bull HG, Hawes BE, Burnett DA, Braun MP, et al The target of ezetimibe is Niemann-Pick C1-Like 1 (NPC1L1). Proc Natl Acad Sci USA (2005) 102:8132-7. doi: 10.1073/pnas.0500269102

10. Asbach P, Paetsch I, Stawowy P, Sander B, Fleck E. Statin-associated focal myositis. Int J Cardiol (2009) 133:e33-4. doi: 10.1016/j.ijcard.2007.08.109

11. Wagner M, Muhldorfer-Fodor M, Prommersberger KJ, Schmitt R. Statininduced focal myositis of the upper extremity. A report of two cases. Eur J Radiol (2011) 77:258-60. doi: 10.1016/j.ejrad.2010.12.031

12. Garcia-Valladares I, Espinoza LR. Ezetimibe-induced relapsing polymyositis. J Rheumatol (2010) 37:472. doi: 10.3899/jrheum.090660

13. Ye X, Zhang G, Righolt C, Johnston JB, Banerji V, Gibson SB, et al. Associations between statin use and risk of non-Hodgkin lymphomas by subtype. Int J Cancer (2018) 143:971-9. doi: 10.1002/ijc.31373

14. Vallianou NG, Kostantinou A, Kougias M, Kazazis C. Statins and cancer. Anti-cancer Agents Med Chem (2014) 14:706-12. doi: 10.2174/1871520613666131129105035

15. Demierre MF, Higgins PD, Gruber SB, Hawk E, Lippman SM. Statins and cancer prevention. Nat Rev Cancer (2005) 5:930-42. doi: 10.1038/nrc1751
16. Murai T. Cholesterol lowering: role in cancer prevention and treatment. Biol Chem (2015) 396:1-11. doi: 10.1515/hsz-2014-0194

17. Murata M. Inflammation and cancer. Environ Health Prev Med (2018) 23:50. doi: 10.1186/s12199-018-0740-1

18. Singh R, Mishra MK, Aggarwal H. Inflammation, Immunity, and Cancer. Mediators Inflammation (2017) 2017:6027305. doi: 10.1155/2017/6027305

19. Michiels S, Dierickx D, Taelman V, Tousseyn T, Lenaerts J, De Langhe E. One biopsy, two diagnoses: statin-induced autoimmune myopathy in combination with extranodal marginal zone lymphoma. Clin Exp Rheumatol (2017) 35:717.

Conflict of Interest: The authors declare that the research was conducted in the absence of any commercial or financial relationships that could be construed as a potential conflict of interest.

Copyright (c) $2021 \mathrm{Wu}, \mathrm{Xu}$ and Wang. This is an open-access article distributed under the terms of the Creative Commons Attribution License (CC BY). The use, distribution or reproduction in other forums is permitted, provided the original author(s) and the copyright owner(s) are credited and that the original publication in this journal is cited, in accordance with accepted academic practice. No use, distribution or reproduction is permitted which does not comply with these terms. 